\title{
Seloko Sebagai Media Komunikasi Dakwah Masyarakat Desa Limbur Merangin Kecamatan Pamenang Barat Kabupaten Merangin
}

\author{
Khoirun Nasbih, Dian Mursyidah, Nurbaiti, Zulqarnin \\ UIN Sulthan Thaha Saifuddin Jambi \\ Email: nurbaiti@uinjambi.ac.id
}

\begin{abstract}
Abstrak: Penelitian ini dilatar belakangi oleh realita yang terjadi di masyarakat yaitu antara masyarakat di pedesaan yang masih mengimplementasikan seloko, sebaliknya di daerah perkotaan seloko sudah mulai memudar sehingga baik keberadaan maupun nilainya yang seharusnya tertanam dalam jati diri masyarakatnya justru terjadi sebaliknya. Pendekatan penelitian yang penulis gunakan adalah pendekatan kualitatif dengan tipe penelitian deskriptif. Penelitian dengan teori deskriptif merupakan uraian sistematis teori dan hasilhasil penelitian yang relevan dengan variabel yang akan diteliti. Untuk mendapatkan data yang akurat dan relevan dengan objek penelitian maka penulis menerapkan tiga metode pengumpulan data yaitu, observasi lapangan, wawancara, dan dokumentasi. Adapun hasil yang diperoleh penulis adalah pertama, komunikasi dakwah menggunakan seloko di nilai efektiv karna bisa membuat para komunikan menjadi tertarik dan merasa nyaman, selain itu juga membuat substansi dari informasi yang disampaikan dapat lebih mudah dipahami oleh para komunikan. Kedua, komunikasi dakwah dengan seloko juga bermanfaat, karna kandungan seloko sendiri berisi ungkapan yang meliputi peraturan bertingkah laku dalam kehidupan sehari-hari masyarakatnya dan kaedah-kaedah hukum atau norma-norma, yang senantiasa dita'ati dan di hormati oleh masyarakatnya karena mempunyai sanksi. Menerapkan substansi dari seloko tersebut berarti sama saja menerapkan adat yang berlaku di daerahnya masing-masing.

Kata-kata Kunci: seloko, Komunikasi, Dakwah, Seloko.
\end{abstract}

\section{A. Pendahuluan}

Indonesia merupakan Negara yang kaya akan budaya, dari segi bahasa, sastra, adat istiadat, suku bahkan agama yang beragam. Terkhusus di Provinsi Jambi, dahulu Provinsi Jambi adalah pusat kebudayaan, ada dua kerajaan besar 
yang berkembang di wilayah Jambi, yaitu kerajaan melayu dan Jambi. Tiap-tiap kebudayaan menghasilkan kebudayaan sendiri-sendiri. Ada beberapa bentuk peninggalan yang membuktikan hal tersebut seperti situs karang berahi di Merangin, Candi Muaro Jambi, makam raja raja, dan bentuk stupa budha sebelum zaman kerajaan ini, wilayah Jambi telah dihuni oleh manusia prasejarah beberapa bentuk peninggalan dapat ditemukan di wilayah Jambi, seperti batu megalitik di sekitar danau kerinci dan gua purba. Suku-suku bangsa asli Jambi juga memiliki budaya yang khas dan indah. Sampai saat ini kebudyaankebudayaan itu ada yang hidup terpelihara di tengah-tengah masyarakat. Sebagian lagi kebudayaan itu sudah langka di temui. ${ }^{1}$

Salah satu budaya Jambi yang sangat populer di tengah masyarakat adalah seloko adat, yang mana seloko adat ini merupakan salah satu jenis sastra yang ada dalam sastra Adat Jambi. Seloko adat Jambi adalah ungkapan yang mengandung pesan, atau nasihat yang bernilai etik dan moral. Serta sebagai alat pemaksa dan pengawas norma norma masyarakat agar selalu dipatuhi. Isi ungkapan seloko adat Jambi meliputi peraturan bertingkah laku dalam kehidupan sehari-hari masyarakatnya dan kaidah-kaidah hukum atau normanorma senantiasa di ta'ati dan di hormati oleh masyarakat karna mempunyai sanksi. Adapun di dalam kehidupan bermasyarakat, bahasa sastra atau seloko ini sangat baik untuk di gunakan karena sebagai salah satu cara untuk menyampaikan masalah yang bersifat tegur sapa, peringatan dan lain-lain. Begitu pula dalam kegiatan yang memakai upacara adat atau menggunakan prosesi adat, dialognya dilakukan dengan bahasa sastra, yang disampaikan dalam bentuk seloko, dan bahkan pantun juga di pakai sebagai salah satu jenis sastra adat. Pemakaian bahasa sastra atau seloko ini dimaksudkan agar terdengar indah, menyentuh hati, kemudian agar tidak menyinggung perasaaan bagi yang terkena

\footnotetext{
${ }^{1}$ Hasip Kalimuddin Syam, Pokok-Pokok Adat Pucuk Jambi Sembilan Lurah Jilid I Sejarah Adat Jambi,(Lembaga Adat Provinsi Jambi, 2001) 15.
} 
sasaran dan maksud dari ungkapan seloko tersebut, kemudian juga agar tidak terdengar kasar oleh khalayak yang hadir.

\section{B. Seloko sebagai Komunikasi Dakwah}

Seloko adat adalah ungkapan yang mengandung pesan, atau nasehat yang bernilai etik dan moral, serta sebagai alat pemaksa dan pengawas norma-norma masyarakat agar selalu di patuhi. Dalam KBBI adat berarti aturan (perbuatan dan sebagainya) yang lazim diturut atau dilakukan sejak dahulu kala. ${ }^{2}$ Jadi, Seloko adat merupakan sastra adat Jambi yang berisikan petuah-petuah untuk keslamatan dan kebaikan kehidupan bagi masyarakat. ${ }^{3}$ Isi ungkapan seloko adat meliputi peraturan bertingkah laku dalam kehidupan sehari-hari masyarakatnya dan kaedah-kaedah hukum atau norma-norma, senantiasa dita'ati dan di hormati oleh masyarakatnya karena mempunyai sanksi.

Seloko adat sebagai ekspresi bermakna ganda yaitu tidak terbatas pada struktur naratif yang tersurat, tetapi ada dimensi-dimensi yang tersirat. Teks-teks seloko adat tidak hanya di mengerti secara harfiah tetapi di tafsirkan secara simbolik dan metafisik. Tujuannya adalah untuk mencari makna yang disampaikan lewat teks tersebut yang berupa konsepsi filosofi (konsep paling dasariah mengenai hakikat manusia, dunia, dan tuhan). Dengan kata lain dalam makna harfiah atau literal, primer yang secara langsung di tunjukkan. Bersamaan dengan itu di tunjukkan pula makna lain yang tidak langsung sekunder, kiasan hanya dapat di pahami berdasarkan makna yang pertama. ${ }^{4}$

Media merupakan alat bantu yang memudahkan proses komunikasi. Media bisa berupa indra manusia, telepon, surat, telegram, media massa (cetak

2 Tim Penyusun Kamus Pusat Pembinaan dan Pengembangan Bahasa, Kamus Besar Bahasa Indonesia Edisi Kedua, (Jakarta, Balai Pustaka, 1993), 6.

${ }^{3}$ Hasip Kalimuddin Syam, Pokok-Pokok Adat Pucuk Jambi Sembilan Lurah Jilid III Sastra Adat Jambi, 9.

${ }^{4}$ Bahren Nurdin, "Seloko Adat Melayu Jambi Potret Zaman", diakses melalui alamat http://bahren13.wordpres.com/2014/01/12/seloko-adat-melayu-Jambi/ pada hari Kamis, 09 Mei 2019 pukul 01.09 WIB. 
elektronik), internet, rumah ibadah, pesta rakyat dan alat bantu lainnya dalam menyebarkan pesan komunikasi. Dengan demikian, media adalah alat bantu untuk memindahkan pesan dari komunikator kepada penerima pesan. ${ }^{5}$ Adapun pengertian daripada komunikasi menurut Everett M. Rogers adalah proses di mana suatu ide dialihkan dari sumber kepada satu penerima atau lebih, dengan maksud untuk mengubah tingkah laku mereka. ${ }^{6}$

Dakwah berasal dari bahasa arab yang artinya, ajakan, seruan panggilan, undangan. Beberapa makna dakwah secara bahasa adalah (a) An-Nida artinya memanggil; da'a fulanun ila fulanah, artinya si fulan mengundang si fulanah, (b) Ad-du'a lla syai'l artinya menyeru mendorong pada sesuatu, (c) Ad-da'wat ila qadhiyat artinya menegaskan atau membelanya baik terhadap yang haq ataupun yang batil. ${ }^{7}$ Selanjutnya pengertian dakwah secara umum ialah, suatu pengetahuan yang mengajarkan seni dan tehnik menarik perhatian orang guna mengikuti suatu ideologi dan pekerjaan tertentu, atau dengan kata lain ialah ilmu yang mengajarkan cara-cara mempengaruhi alam fikiran manusia. dakwah berusaha menyebrangkan alam fikiran manusia kepada suatu ideologi tertentu.

\section{Sejarah Desa Limbur Merangin}

Adapun asal nenek moyang orang limbur merangin sekarang tidak di ketahui secara pasti, dari mana sumber yang saya dengar bermacam-macam pendapat. Ada yang mengatakan asalnya dari Mataram beragama Hindu, ada pula yang mengatakan dari Palembang dan sebagainya, yang jelas dua suku pendatang yang ada perbedaan bahasanya. Mereka mendirikan rumah dan bermukim di Dusun Tuo. Jumlahnya waktu itu ham 7 buah rumah. Menurut sahibul hikayat semasa buluh masih berbuah ago, bakul nyiru, air sebelah sini 48.

${ }^{5}$ Nurudin, Ilmu Komunikasi Ilmiah dan Populer, (Jakarta, PT RajaGrafindo Persada, 2016),

${ }^{6}$ Nurudin, Ilmu Komunikasi Ilmiah dan Populer, 38.

${ }^{7}$ Jum'ah Amin Abdul 'Aziz, Fiqih Dakwah Prinsip dan Kaidah Asasi Dakwah Islam, (Solo, Era Intermedia, 2005), 24. 
hanyut ke ilir, sebelah sana hanyut ke mudik. Setelah di sapa si Pahit Lidah, buluh tidak lagi berbuah ago, bakul, nyiru dan air hanyut ke ilir semuanya. ${ }^{8}$

Berapa lama mereka bermukim di Dusun Tuo tidak di ketahui, tanda mereka cukup lama berada di sana adanya pendam pekuburan cukup banyak di Bukit Sungai Nawa. Setiap warga Dusun Tuo ada yang meninggal jenazahnya di kebumikan di Bukit Sungai Nawa. Kata pepatah mati di anta katanah layu. Sampai sekarang batu-batu nisan di Bukit Sungai Nawa masih dapat kita jumpai bukti adanya peradaban nenek moyang masa silam. Pada suatu hari waktu mengambil daging ular biyang ular biyung salah seorang orang Pulau Jalia sengaja melait(menyayat) sedikit hati ular biyang ular biyung tersebut. Merasa hatinya di sayat melampau pantang yang setiap hati di pcringatkan, maka pada malam hatinya hujan lebat, kilat sambar menyambar, guruh petir sambung menyambung ular biyang membuka gelung. Kata pepatah baungkai simak tali, babukak simak pintu lalu turun ke air terus balayia (berlayar) menghulu batang mangin kabarnya masuk Danau Kerinci ular tersebut apa sekarang masih hidup atau sudah mati wallahu a'lam. Besok harinya penduduk Dusun Tuo terkejut melihat jamban, biduk mereka terdampar di atas tebing, air Merangin sangat keruh. Apa gerangan yang terjadi...? Maka berbondong-bondonglah orang Dusun Tuo mudik. Setibanya di tempat ular biyang ular biyung tersebut ternyata ular besar tersebut telah pergi meninggalkan tempat tinggalnya selama ini. Tanah tempat ia turun longsor, itu yang membuat air sangat keruh. Sesuai kata pepatah kehuh ayik cingok ka ulu smak ayik cingok ka moho. ${ }^{9}$

Jauh sebelum Belanda memasuki Merangin, pejuang-pejuang yang menjadi hulubalang raja Mesumai umumnya pandai ilmu silat seni beladiri. Nama silat diantaranya adalah: Kuntau, Kamiyan, Tembung dan lain-lain. Mereka mahir main tangan, kaki, keris, pedang, kayu dan sebagainya. Setelah tamat mereka menuntut ilmu batin seperti kebal, apung (tahan pukul), panheh (tinju

\footnotetext{
${ }^{8}$ Haramaini HY, Sejarah Terjadinya Desa Limbur Merangin, (Bukit Penantian, 2010), 4.

${ }^{9}$ Haramaini HY, Sejarah Terjadinya Desa Limbur Merangin, 5.
} 
bisa), rantai sakilan, pancung ramayong dan banyak lagi yang lainnnya. Mereka menamakan diri budak ulu. Bila ke Jambi ada yang dari Siau, Sungai Tenang, Jangkat, Serampas, RantauPanjang, Sei. Manau, Merangin dan sekitarnya tak ketinggalan dari dusun Limbun Bungin. Selain menjadi hulubalang raja banyak juga yang hobi menyabung ayam. Mereka mengundang peningka(pendekar) dari Bungo, Kerinci, Palembang, Mnah Isau (Orang buangan). Tempat mereka menyabung ayam yaitu di muara merangin. Mereka membawa nasi bungkus dalam upih, ayam jago termasuk membawa senjata keris, pisau, badik, pedang, kayu dan sebagainya. Sesampainya di muara merangin mereka mulai menyabung ayam, bila salah satu ayam yang di adu ada yang kalah maka orang yang ayamnya kalah melompat masuk gelanggang sambil mencabut senjatanya mencari lawan, maka orang yang ayamnya menang tersinggung maka gayung bersambut kata berjawab melompat pulalah dia sambil mencabut senjatanya. ${ }^{10}$

Mereka bertarung mati-matian. Banyak para pendekar mati basabung di muara merangin. Mereka mati tidak terkubur sehingga tulang belulang dan tengkorak mereka berserakan di atas tanah. Kepala manusia seperti niyoa tukak (buah kelapa yang di makan tupai). Kata pepatah:

Mati di padang telentah imbo balung Kumpulan paku penyamunan

Mati di tangis ungko kelabu

Mati di atap langau ijau

Dak di pendam ba pakuburan

Dak di tanam puding dengan jaluang

Luko dak mintak pampeh

Mati dak mintak bangun

Sengaja balalap gadung matah

Batempah kapayang mabuk

${ }^{10}$ Ibid., 16. 
Sampai sekarang paku yang tumbuh di tempat menyabung di muara merangin kapan di ambil di cium masih berbau amis darah. Selain di muara merangin tempat mereka menyabung ayam dan menyabung nyawa yaitu di Batu Penyabung Kabupaten Sarolangun sekarang. Peningka(pendekar) dari dusun Limbun Bungin tak pernah absen pergi menyabung. Umumnya budak ulu pada masa itu jarang yang luka apa lagi sampai mati. Memang biduk lentik lah tahan di saing kaji baik lah tahan pulo untuk di simak.

Suatu ketika sewaktu peningka dari ulu telah meletakkan ayamnya di gelanggang begitu juga dengan peningka yang di undang. Ayam sudah berkokok siap berlaga timbullah kesadaran dari peningka yang di undang, maka di tangkapnya ayamnya kembali.

Sebelum Belanda masuk dan menguasai Merangin di adakan rapat di Ujung Tanjung Muara Mesumai yang di pimpin oleh Pangeran Tamenggung anak Raja Mesumai. Banyak urusan ninek mamak tuo tau serta hulubalang wakil dari dusun masing-masing di wilayah Merangin. Di hari yang di tetapkan maka di panggillah segala cerdik pandai serta para hulubalang untuk menghadap Raja Mesumai di Ujung Tanjung Muara Mesumai. Setelah rapat di buka oleh Raja Mesumai yang hadir ketika itu mulai mengeluarkan pendapat tentang menghadapi Belanda yang akan menyerang Merangin dan Bangko sampai ke Muara Bungo. Macam-macam pendapat yang di hasilkan, ada yang mengatakan kita menyerah saja kepada Belanda usah di ungkit batu lekat tamilang kita nang ka kupak. Ada pula yang mengatakan kita menyerah dan mengibarkan bendera putih di Muara Merangin tanda tunduk, kalau menyerah rakyat aman dan harta bendapun aman. Raja Mesumai diam saja mendengar pendapat pendapat ninek mamak tuo tau.

Wakil dari Dusun Limbun Bungin juga hadir ketika itu yaitu H. Sukur Bapak H. Ja'far nenek H. Hamid mantan kades desa Limbur Merangin. H. Sukur terakhir sekali mengeluarkan pendapat, katanya pendapat yang terdahulu tadi semuanya benar kalau kita menyerah kita akan aman kalau perang kita akan rugi, tapi kalau 
pendapat ngan kito cubo nungkek tuah di galanggang, nampin tahuh dengan kuyu, cubo nungkat langit dengan talutuk, mungka gunung dengan tamilang lidi, kito cubo nanam mumbang, kalu hidup jadi payung negeri, kito mueh hati nan sakali, nyenang panano nan mabuk, lebih dari itu kita minta pula pendapat Raja sebab nyo nan balidah masin bapahang tajam bajalan dulu salangkah bakato dulu sapatah nyo pula nan tuah keris nan di tangkil, tuah pedang nan di sandang, nyo nan duduk di bawah payung nan sakaki kembang diatas mahligai sabatang tegak, tuah puti pindah memindah tuah rajo turun temurun, duduk ngkoh nyadi rajo tegak nyadi hulubalang, nyo nan megang tombak nan bacangkah lambing kekuasaan rajo masumai.

Setelah H. Sukur berhenti dari berbicara panjang lebar Raja Mesumai termenung, menengadah dan menunduk di keribaannya. Tuanku raja telah basah oleh air mata rupanya beliau menangis. Setelah lama raja merenung akhirnya dia berkata: posisi kita kini sama dengan dang dangkek basahang di umpun buluh, di adang kito luko empat kalu di ilak luko tujuh, kalau meminta pendapat dari ngan selaku raja sesuai dengan pendapat wak $\mathrm{H}$. Sukur dari dusun Limbun Bungin tadi. Minta pendapat dari raja. Kalau menurut ngan kalau menyerah pada belanda yo ngan pahit minum air merangin dari kita hidup dijajah, lebih baik mati bagalang tanah. Kalau begitu kata Raja kalau berlek kita pungko(bermodal) perang kita junjung, celak phang(perang) di pancung rajo, sengketo negeri di hukum batin, maka kita bunyikan kemong/bende(gong) di panggil dibalang nan 40 bawa tentara sagantang bijan kita songsong ke Muara Merangin sambil membawa semua senjata yang ada kita perang sabil mempertahankan harga diri dan tanah pusaka, kok kereh(keras) sama kita takik kok lunak sama kita sudu. ${ }^{11}$

Sebelum Belanda memasuki Merangin, rakyat di dusun-dusun di suruh pindah (mengungsi) ke hutan. Rakyat Dusun Limbun Bungin pun demikian mereka pindah ke hutan belantara yaitu di daerah payo(rawa) langantuk, payo ujo mereka bermukim di tepi sungai. Sungai itu di namakan Sungai Suko Iram

\footnotetext{
${ }^{11}$ Ibid., 19.
} 
yang artinya tempat bersenang-senang. Walaupun hidup di dalam hutan tetapi mereka merasa bebas/merdeka. Dusun Limbun Bungin khususnya sudah lama di tinggalkan penduduknya, saking lamanya di dusun telah menjadi padang langgui (rimbang, terung pipit). Di saat Belanda masuk Merangin berdentumlah bunyi bedil kedua belah pihak. Bedil meletus bunyi maka babuluh. Tempat perang di Merangin yaitu di Mampun Pamenang, Renah Pelayang Jelatang dan Lubuk Lesung Limbun Bungin karena marah pada para pejuang yang banyak membunuh serdadunya belanda ngapak (membabat) tiang rumah orang dusun Limbun Bungin, tiang bulian bekas kapak masih ada hingga sekarang yang menjadi tiang rumah $\mathrm{Hj}$. Isyah Kapuk. Dua bulan perang di air dan tiga bulan perang di darat akhirnya tentara kita kalah. Malang tak dapat di tolak mujur tak dapat di raih karena bedil kita sepucuk dua Yang lain membawa tombak, pedang, bambu runcing, umban dan sebagainya Sedangkan Belanda lengkap senjatanya. Di Dusun Limbun Bungin ditangkaplah oleh Belanda H. Sukur kakak dari Bakar Juhul. Karena kakaknya H. Sukur sudah tua Bakar bapak Mat Bayat nyerah diri. Pak Limin meneruskan perang gerilya di hutan-hutan.

Jauh sebelum Belanda masuk menguasai merangin bahwa di ulu merangin ada sebuah dusun yang tokoh masyarakatnya sakti mandraguna membantu raja-raja Jambi sebelum Sultan Thaha mereka pergi ke jambi masuk para pejuang yang di pimpin raja-raja Jambi mengusir penjajahan Belanda dari bumi Sepucuk Jambi Sembilan Lurah. Dusun yang di maksud Belanda Limbur Merangin Yaitu dusun Limbun Bungin lidah orang-orang Belanda tidak bisa menyebut Limbun Bungin yang terucap tetap saja Limbur Merangin, Limbun tuan kata orang dusun Limbur kata orang Belanda. Bungin tuan yang terucapnya merangin oleh mereka. Bagaimana juga di ulang-ulang dia tidak bisa menyebut dusun Limbun Bungin yang terucap tetap saja Limbur Merangin maka berubah pulalah nama dusun Limbun Bungin menjadi Limbur Merangin sampailah sekarang. ${ }^{12}$

12 Ibid., 22. 


\section{Respon Masyarakat terhadap Efektivitas Seloko sebagai Transmisi Budaya}

Suatu komunikasi bisa dikatakan efektiv apabila memiliki 6 unsur yaitu komunikator, pesan, media, komunikan, feedback (respon), dan dampak (efek). Namun dalam hal ini yang menjadi fokus pembahasan kita yakni mengenai respon dan dampak. Respon merupakan jawaban komunikan atas pesan yang di berikan oleh komunikator kepadanya. Sedangkan dampak atau efek merupakan perubahan yang di alami oleh komunikan sebelum dan sesudah menerima pesan.

Komunikasi yang efektiv biasanya memiliki tujuan untuk memudahkan orang lain dalam memahami pesan yang disampaikan oleh seseorang pemberi pesan. Komunikasi dakwah dengan menggunakan seloko dinilai dapat memudahkan para komunikator atau da'i dalam menyampaikan dakwah dan komunikan dalam memahami maknanya. Bahkan di desa Limbur Merangin penggunaan seloko sebagai media komunikasi tak hanya di lakukan dalam kegiatan keagamaan saja namun dalam lingkungan berkeluarga dan bermasyarakat acap kali di gunakan.

Membahas respon masyarakat mengenai penggunaan seloko dalam komunikasi dakwah ini seorang da'i dari desa Limbur Merangin Tengku Iskandar Manaf, menjelaskan antusias dari para mad'u ketika mendengar ceramah dari beliau bahkan ia menjelaskan juga ada yang masih ingat materinya hingga tiga tahun kedepan. Ketika saya berdakwah masyarakat sering manyampaikan "Tengku kalau mau ceramah besok jangan lupa bawa seloko adatnya, kalau perlu lagu daerahnya, suara Tengku itu bagus", kadang-kadang orang akan mengenang itu ketimbang ayat al-Qur'an dan Hadist Nabi. Kadang-kadang musim maulid tahun ini sampai tahun depan ia masih ingat. Ada saya menyampaikan ceramah di suatu daerah tiga tahun yang lalu, ketika saya di undang lagi ia masih ingat dengan apa yang saya sampaikan. ${ }^{13}$

${ }^{13}$ Mudir Ponpes Mambaul Ulum Desa Limbur Merangin, Tengku Iskandar Manaf, Wawancara, catatan Lapangan 23 Januari 2020. 
Keadaan yang terjadi antara Tengku Iskandar dan para jama'ahnya tersebut dialam komunikasi antar agama dan budaya, di sebut dengan homofili. Homofili adalah suatu keadaan yang menggambarkan derajat pasangan perorangan yang berinteraksi yang memiliki kesamaan dalam sifat (attribute), seperti dalam kepercayaan, nilai, pendidikan, status sosial, dan sebagainya. Prinsip Homofili adalah sejauh mana pasangan yang berinteraksi itu mirip dalam ciri-ciri tertentu. Komunikasi yang efektif seperti itu menyenangkan orang-orang yang terlibat didalamnya. Bila dua orang bertukar makna, kepercayaan yang sama dan bahasa yang mereka pergunakan sama, komunikasi antar mereka cenderung lebih lancar. Komunikasi yang tidak sama (heterofilus) bisa menyebabkan ketakserasian pandangan karena seseorang dihadapkan pada pesan yang tidak cocok dengan perspektif mereka dan bisa menyebabkan miss komunikasi. Oleh karna itu mengapa antara jama'ah dan da'i yang disampaikan oleh tengku iskandar tersebut mereka sangat antusias dalam mendengar materi ceramahnya karena ada kesamaan dalam bahasa. Sedikit banyaknya pesan yang di sampaikan dalam materi ceramah tersebut tentu memiliki dampak terhadap para komunikan, ini juga di jelaskan oleh Tengku Iskandar Manaf dalam penuturannya.

Ketika membahas mengenai cara berpakaian sesuai dengan syari'at Islam, contohnya seperti kerudung, jilbab, kalau bahasa dusun disebut tekuluk. Hal tersebut, menurut hukum, itu adalah suatu kewajiban menurut seorang perempuan, untuk keluar rumah ketika ia berhadapan dengan orang yang bukan mahram itu harus menutup aurat, menutup kepala. Kemudian kita bahas dari segi adat, bahwa salah satu fungsi tekuluk itu ialah pertama, untuk menutup aurat sesuai dengan syari'at, yang kedua menunjukkan bahwa kita ini orang baik sementara orang tidak tau apa yang kita lakukan maka orang akan menilai secara dzohir bahwa kita ini orang baik, yang ketiga fungsi tekuluk tadi ialah tanda kita menghormati orang tua, maka anak kemenakan kita ketika datang ke rumah mamaknya atau datuknya dengan tidak menggunakan tekuluk maka secara tidak 
langsung ia tidak mengormati orang tua tersebut. setelah saya dakwahkan masalah tersebut sejalan antara agama dengan adat dampaknya alhamdulillah sekarang banyak orang yang berubah untuk menggunakan kerudung atau tekuluk, paling tidak ketika lebaran, paling tidak ketika undangan, yang hariannya ia belum menggunakan kerudung, tapi setelah hari baik buan baik, ia datang kerumah mamaknya jadilah ia berubah secara musiman dulu sebelum ia berubah total. Paling tidak pula ketika ia datang ke ceramah bertemu saya dia malu sendiri jika tidak menggunakan tekuluk. Itulah dampak positifnya. ${ }^{14}$

Adapun respon masyarakat mengenai penerapan adat melalui seloko, bang Saipul Islami dalam penuturannya mendukung dan berharap seloko ini tidak hanya sekedar di petatah petitihkan saja, namun hendaknya juga di amalkan dalam kehidupan sehari-hari. Antara agama dan adat itu hendaknya di satukan, lalu di jelaskan dengan petatah petitih atau seloko supaya tujuannya untuk merubah adab dan akhlaqul karimah serta bisa menumbuhkan sifat ta'at bisa terwujud. Bagus jika petatah petitih ini ketika di terapkan di masyarakat, walaupun masyarakat kita sudah majemuk, telah bercampur suku jawa, melayu, minang dan lain sebagainya. Tetapi walaupun bercampur, di sinilah letak penerapan nilai dari seloko yang berbunyi "di mano bumi di pijak, di situ langit di junjung, di mano tamilang di cacak, di situ tanaman tumbuh", dari manapun asalnya jikalau sudah berdomisili di Desa Limbur Merangin, maka mereka harus bisa mengikuti adat yang berlaku di desa tersebut. Sehingga adat tersebut tidak mati dan anak keturunan bisa menerapkannya bukan malah untuk di kenang. ${ }^{15}$

Seloko di nilai sangat bermanfa'at karna maknanya yang berisi nasihat, dan sangat berguna jika diterapkan dalam lingkungan bermasyarakat untuk mengenalkan adat terhadap anak dan untuk memperbaiki akhlaq, hal tersebut di benarkan dalam penjelasan ibu rumah tangga yang bernama NurAzizah. Sasaran daripada komunikasi seloko ini cukup bervariasi mulai dari anak muda hingga

\footnotetext{
${ }^{14}$ Ibid, Tengku Iskandar Manaf.

${ }^{15}$ Warga Desa Limbur Merangin, Saiful Islami, wawancara, catatan lapangan, 24 Januari 2020 .
} 
orang dewasa, karna sifatnya yang universal cocok untuk segala kalangan usia. Sehingga dampaknya pun tidak hanya di rasakan oleh orang dewasa saja, seorang pemuda yang bernama Razan Ikram Amali, menjelaskan hal tersebut dalam penuturannya. Penggunaan seloko ini bagus, karna ia memiliki makna berupa nasihat, petatah, kato nan tuo-tuo yang memberikan pengajaran kepada kita untuk mengetahui mana yang baik dan mana yang buruk. Seloko ini digunakan bukan hanya dalam upacara adat saja namun juga sering di gunakan dalam pengajian tentunya untuk memberi petunjuk dan arahan kepada kita. ${ }^{16}$

Beberapa pernyataan dari berbagai narasumber tersebut, menerangkan pentingnya menggunakan seloko dalam kehidupan bermasyarakat dan berkeluarga, karna selain untuk memperbaiki akhlaq, tapi juga untuk melestarikan adat supaya tidak hilang di telan zaman. Sehingga anak keturunan kita tidak terpengaruh oleh pergeseran budaya buruk dari luar yang dapat merubah tradisi baik yang sudah ada sejak lama, serta tidak menganggap seloko sebagai suatu budaya yang kuno.

\section{E. Kendala Menyampaikan Seloko Sebagai Media Komunikasi Dakwah}

Ada faktor pendukung dalam sebuah proses komunikasi, sebaliknya ada pula faktor penghambat atau kendala dalam komunikasi dakwah dengan seloko. Adapun faktor penghambatnya ialah sebagai berikut:

Pertama guru Iskandar Manaf memberikan penjelasan terkait kendala ketika berceramah dengan seloko yaitu: tentu ada kendala ketika menyampaikan materi ceramah dengan seloko, terus terang saya kekurangan bahasa tentang seloko kemudian kendala ketika kita berdakwah di tempat orang lain, karna kadang-kadang seloko itu tidak sama bunyinya ada juga yang berselisih paham dengan seloko itu, contohnya begini "dianjak layu anggo mati" ini bahasa kita wilayah Pamenang, berbeda dengan daerah Rantau Panjang "diasak layu dianggo mati" kemudian di daerah orang Minang mereka bilang bukan "dianjak

\footnotetext{
${ }^{16}$ Warga Desa Limbur Merangin, Razan Ikram Amali, wawancara, catatan lapangan, 26 Januari 2020.
} 
layu dianggo mati" itu tanaman sementara adat itu "dianjak tidak layu dianggo tidak mati" ada penambahan kata tidak, inilah yang menjadi kendala tapi kendala ini tidak menjadi masalah yang fatal terkadang orang akan mengerti karna kita masih satu batang sungai. ${ }^{17}$

Komunikasi merupakan keterampilan paling penting dalam hidup setiap manusia. Komunikasi juga di butuhkan sebagai pemahaman atas pesan yang disampaikan oleh komunikator juga di perlukan. Jika tidak maka komunikasi yang dilakukan tidak akan efektiv. Pentingnya penguasaan tentang bahasa seloko ini akan, sangat membantu proses komunikasi, sehingga pesan yang kita sampaikan dapat dengan mudah diterima oleh masyarakat. Maka para pelaku komunikasi terkhusus da'i, diharapkan dapat menggali dan menguasai salah satu satra adat yaitu seloko ini, untuk memperkuat dalil materi dakwahnya, karna hal tersebut merupakan salah satu cara berdakwah paling jitu saat ini.

Kedua tidak ada usaha dari anak muda untuk mempelajari ilmu itu. Seiring perkembangan zaman, maka semakin maju juga teknologi yang ada. Hal tersebut memudahkan kita mengakses semua hal, termasuk dalam hal kebudayaan. Baik dalam hal kebudayaan lokal dan kebudayaan asing. Sehingga dalam prosesnya terciptalah sebuah akulturasi. Akulturasi adalah suatu proses sosial yang timbul manakala suatu kelompok manusia dengan kebudayaan tertentu dihadapkan dengan unsur dari suatu kebudayaan asing. Kebudayaan asing itu lambat laun diterima dan diolah ke dalam kebudayaannya sendiri tanpa menyebabkan hilangnya unsur kebudayaan kelompok itu sendiri.

Akan tetapi sebuah akulturasi yang seharusnya memadukan dua kebudayaan dengan tidak menghilangkan kebudayaan dari kelompoknya sendiri, malah terjadi sebaliknya. Anak muda sebagai generasi penerus bangsa, yang akan melanjutkan estafet dalam berbagai macam aspek kehidupan di masa mendatang. Karna proses akulturasi, malah tidak sedikit pemuda merasa nyaman

17 Mudir Ponpes Mambaul Ulum Desa Limbur Merangin, Tengku Iskandar Manaf, Wawancara, catatan Lapangan 23 Januari 2020. 
dengan kebudayaan baru yang terbentuk, dan lambat laun malah berfikir kebudayaannya sendiri merupakan suatu hal yang kuno.

Akibatnya minat untuk mempelajari kebudayaannya sendiri menjadi berkurang, salah satunya untuk mempelajari seloko. Pelakunya malah lebih tertarik berkomunikasi menggunkan bahasa asing dari pada menggunkan seloko yang mengandung nasihat, karna bahasa asing di nilai lebih gaul, keren dan sesuai dengan perkembangan zaman. Pegawai syarak Haramaini juga berpendapat faktor tersebut menyebabkan tidak adanya upaya untuk mempelajari seloko dan tidak adanya rasa memiliki, sehingga ketika gurunya meninggal ikut terkubur pula keahlian atau bahasa indah tersebut dari mereka. ${ }^{18}$

Ketiga minimnya guru yang ahli terhadap seloko, faktor ini menjadi salah satu kendala dalam penerapan komunikasi dakwah menggunakan seloko. kurangnya antusias pemuda dalam mempelajari seloko, sehingga guru yang bisa dikatakan senior dan ahli dalam komunikasi seloko ini, satu persatu meninggal seiring perkembangan zaman, maka komunikasi seloko pun menjadi langka.

\section{F. Penutup}

Berdasarkan hasil penelitian tentang Seloko Sebagai Media Komunikasi Dakwah Di Desa Limbur Merangin Kecamatan Pamenang Barat Kabupaten Merangin maka dapat disimpulkan beberapa hal penting sebagai berikut: pertama, Seloko adat adalah sastra adat Jambi yang berisikan petuah-petuah untuk keselamatan dan kebaikan kehidupan bagi masyarakat. Sedangkan dakwah yang secara bahasa berarti mengajak kepada berbuat baik, sangat serasi jika disandingkan bersama seloko dengan materi ceramah para da'i atau komunikator untuk mengajak ummat kepada arah yang lebih baik dalam kehidupan. Keterkaitan antara seloko dan dakwah banyak digunakan oleh komunikator dan da'i untuk menyampaikan pesan atau materi ceramah.

${ }^{18}$ Pegawai Syarak sebagai Khatib, Haramaini HY, wawancara, catatan lapangan, 23 Januari 2020. 
Pemakaian bahasa sastra atau seloko ini di maksudkan agar terdengar indah, menyentuh hati, kemudian agar tidak menyinggung perasaaan bagi yang terkena sasaran dan maksud dari ungkapan seloko tersebut, kemudian juga agar tidak terdengar kasar oleh khalayak yang hadir. seloko yang di sandingkan dengan materi ceramah juga menjadi salah satu cara yang jitu supaya para komunikan bisa memahami materi dakwah dari dua sisi, atau minimal menjadi solusi jikalau sulit memahami materi dakwah dari sisi agama bisa memahaminya dari sisi seloko. Kedua, penerapan seloko di Desa Limbur Merangin tidak hanya terbatas pada penerapan dalam materi ceramah saja, namun lebih luas dari itu. Mulai dari lingkungan keluarga seloko sudah mulai di kenalkan. Antara orang tua dan anak, seloko di gunakan sebagai media komunikasi untuk memberi nasehat. Kemudian seloko juga digunakan oleh para muda-mudi sebagai media komunikasi untuk mengungkapkan perasaannya, hal itu di lakukan dalam kegiatan seperti berladang, dan bertandang. Ketiga, efektivitas seloko sebagai media komunikasi dakwah dapat diartikan keberhasilan seorang da'i atau komunikator dalam menyampaikan seloko sebagai salah satu media agar para komunikan bisa lebih mudah dalam memahami materi dakwah tersebut, dan semua itu dibuktikan dengan respon dan efek yang timbul setelah dakwah itu di sampaikan. Kehadirannya juga bukan hanya sekedar untuk memperindah bahasa namun juga diharapkan sebagai tameng agar pengaruh buruk budaya asing tidak memperbudak generasi muda. Maka para da'i, pegawai syarak, dan lembaga adat terus mengkomunikasikan seloko yang di gunakan dalam berbagai kegiatan dan terus berupaya dalam mengadakan kegiatan yang menyangkut adat.

\section{Daftar Pustaka}

Tim Penterjemah dan Penafsir Alqur'an. Al-Qur'an dan Terjemahnya. Jakarta: Departemen Agama RI, 2011.

Baqi, Muhammad Fu'ad Abdul. Al-lu'lu' Wal Marjan Himpunan Hadist Shahih Disepakati oleh Bukhari dan Muslim jilid 2. Surabaya : Bina IImu, 1979. 
Ali, Hasan. Pidato Adat. Adat Bersendi Syarak. Syarak Bersendi Kitabullah. Bangko, 1990.

'Aziz, Jum'ah Amin Abdul. Fiqih Dakwah Prinsip dan Kaidah Asasi Dakwah Islam. Solo: Era Intermedia, 2005.

Gemoek, Abdullah. Materi Pembinaan Bagi Pengurus Lembaga Adat Melayu Jambi Bumi Tali Undang Tambang Teliti Kabupaten Merangin. Lembaga Adat Melayu Jambi Bumi Tali Undang Tambang Teliti Kabupaten Merangin, Bangko, 2019.

Haramaini HY. Catatan Buya Haramaini Adat Nan Tasirat Nan Tasurat. Limbur Merangin: Sekdes, 2018.

Haramaini HY. Sejarah Terjadinya Desa Limbur Merangin. Bukit Penantian, 2010.

Muhtadi, Asep Saepul. Komunikasi Dakwah Teori, Pendekatan, dan Aplikasi. Bandung: Simbiosa Rekatama Media, 2012.

Nurudin. Ilmu Komunikasi IImiah dan Populer. Jakarta: RajaGrafindo Persada, 2016.

Pamuk, Raden Marjoyo. Seloko Adat Dalam Pembangunan Dan Kehidupan Sehari-Hari. Lembaga Adat Provinsi Daerah Tingkat I Jambi, Jambi, 1995.

Riduwan. Skala Pengukuran Variabel-variabel Penelitian. Bandung: Alfabeta, 2011.

Salim, Agus. Teori \& pradigma penelitian sosial. Yogjakarta: Tiara Wacana, 2006.

Sugiyono. Metode Penelitian Kuantitatif Kualittatif dan R\&D. Bandung: Alfabeta, 2016.

Syam, Hasip Kalimuddin. Pokok-Pokok Adat Pucuk Jambi Sembilan Lurah Jilid I Sejarah Adat Jambi. Lembaga Adat Provinsi Jambi: 2001.

Syam, Hasip Kalimuddin. Pokok-Pokok Adat Pucuk Jambi Sembilan Lurah Jilid III Sastra Adat Jambi. Lembaga Adat Provinsi Jambi: 2001.

Tim Penyusun Kamus Pusat Pembinaan dan Pengembangan Bahasa. Kamus Besar Bahasa Indonesia Edisi Kedua. Jakarta: Balai Pustaka, 1993.

Tim Penyusun. Panduan Penulisan Karya Ilmiah Mahasiswa Fakultas Ushuluddin IAIN STS Jambi. Jambi :Fak.Ushuluddin lain STS JAMBI, 2016.

Ya'qub, Hamzah. Publisistik Islam Teknik Dakwah dan Leadership. Bandung: c.v. Diponegoro, 1986.

Zulkarnain. "Nilai-Nilai Filsafat Moral Dalam Seloko Adat Perkawinan Jambi di Dusun Pulau Pinang Kecamatan Sarolangun Kabupaten Sarolangun". Skripsi. Program Strata satu Institut Agama Islam Negeri Sulthan Taha Syaifuddin Jambi, 2016. 
Gafar, Abdoel."Peranan Seloko Dalam Upacara Adat Perkawinan Masyarakat Di Kota Jambi". Jurnal Universitas Negeri Jambi (2012), https://online-journal .unja.ac.id/index.php/pena/article/view/1441/935, (diakses 30 November 2019).

Rahima, Ade."Nilai-Nilai Religius Seloko Adat Pada Masyarakat Melayu Jambi". Jurnal Universitas Batanghari Jambi (2014), https://media.neliti.com /media/publication/225562-nilai-nilai-religius-seloko-adat-padamaa196f55d. Pdf, (diunduh 16 Mei 2019).

Cholif, Muchtar Agus. Seminar Seni Budaya Jambi LSHRP 15 Se-Sumbagsel, 5 September 2019.

Observasi awal pada Masyarakat Desa Limbur Merangin 06 November 2019.

Efektivitasadalah - "Pengertian, Rumus, Contoh, Kriteria, Menurut Ahli dan Teori", https://www.dosenpendidikan.co.id, (diakses 04 April 2020).

Lembaga Adat Desa Lubuk Lawas, "Seloko Adat Jambi", http://www.lubuklawas .desa.id/lembaga-adat/, (diakses 04 Desember 2019).

Nurdin, Bahren. "Seloko Adat Melayu Jambi Potret Zaman", http://bahren13. wordpres.com/2014/01/12/seloko-adat-melayuJambi/,(diakses 09 Mei 2019).

Website Resmi Desa Limbur Merangin, http://www.limburmerangin.id/page/sejarah-desa, (diakses 19 November 2019).

Kepala Desa Limbur Merangin, H. Idris, wawancara, catatan lapangan, 24 Januari 2020.

Ketua Lembaga Adat Desa Limbur Merangin, Abu Hasan, wawancara, catatan lapangan, 23 Januari 2020.

Mudir Ponpes Mambaul Ulum Desa Limbur Merangin, Tengku Iskandar Manaf, wawancara, catatan Lapangan 23 Januari 2020.

Pegawai Syarak sebagai Khatib, Haramaini, wawancara, catatan lapangan, 23 Januari 2020.

Pegawai Syarak sebagai Imam, Tengku Zainal Abidin, wawancara, catatan lapangan 25 Januari 2020.

Warga Desa Limbur Merangin, Saiful Islami, wawancara, catatan lapangan, 24 Januari 2020.

Warga Desa Limur Merangin, NurAzizah, wawancara, catatan lapangan, 24 Januari 2020.

Warga Desa Limbur Merangin, Razan Ikram Amali, wawancara, catatan lapangan, 26 Januari 2020. 